\title{
Quantification of Full Range Ethanol Concentrations by Using $\mathrm{pH}$ Sensor
}

\author{
Najah M. Mohammed Al-Mhanna (Corresponding author) \\ Institute of Bioprocess Engineering, Department of chemical and bioengineering \\ University of Erlangen-Nuernberg, Paul-Gordan Str. 3, 91052 Erlangen, Germany \\ Tel: 499-131-852-3017_E-mail: najah.mohammed@bvt.cbi.uni-erlangen.de,najah.almhanna@yahoo.de
}

\author{
Holger Huebner
}

Institute of Bioprocess Engineering, Department of chemical and bioengineering

University of Erlangen-Nuernberg, Paul-Gordan Str. 3, 91052 Erlangen, Germany

Tel: 499-131-852-3006 E-mail: holger.huebner@bvt.cbi.uni-erlangen.de

This work was sported by Institute of Bioprocess Engineering at Erlangen University where the work was done

\begin{abstract}
A differential $\mathrm{pH}$ measurement device was used to achieve operation conditions of alcohol dehydrogenase reaction. Optimum operating conditions were temperature of $30^{\circ} \mathrm{C}, 10 \mu \mathrm{l}$ of alcohol dehydrogenase enzyme volume (with a final activity of 563.75 units $\mathrm{ml}-1)$ per $50 \mu \mathrm{l}$ of sample, $\mathrm{NAD}^{+}$concentration of $0.05 \mathrm{mM}$ and $20 \mathrm{mM}$ glycine-pyrophosphate buffer solution of $\mathrm{pH}$ 9.1. In this method a range of ethanol concentrations from $0-99,985 \%$, which means $0.000001714-17.14 \mathrm{M}$, were used. The maximum obtained change in $\mathrm{pH}$, delta $\mathrm{pH}$, was $(-33) \mathrm{mpH}$. A calibration curve of logarithmic values of ethanol concentrations against change in $\mathrm{pH}$ for standard ethanol samples was done. Since this calibration curve is a linear with a correlation coefficient (R) of 0.998 , this calibration curve can be used in quantification of ethanol concentration. End point of equilibrium concentrations of reactants and products of ethanol oxidation reaction was measured within spectrophotometer. The results indicated 100 seconds of process time is required to reach the end point for all ethanol standard samples. This required time was satisfied with results of measuring change in $\mathrm{pH}$ within differential $\mathrm{pH}$ analyzer system.
\end{abstract}

Keywords: Ethanol analysis, Oxidation enzymatic reaction, Ethanol quantification, Differential pH measurement device

\section{Introduction}

Ethanol is one of the most important substances with different application. For instance, bioethanol is rapidly rising its market share because of application of new technologies i.e. flexible fuel technology. However, for any application of ethanol it is necessary to detect and quantify ethanol with high accuracy. Therefore many methods were used to determine the concentration of ethanol in case when it is either a main product or a byproduct. The available techniques of ethanol detection include gas chromatography, electrochemical and enzymatic assay. The most important methods can be found in previous literatures (Goodman and Jacksonville, 1975; Bauer and Magers, 1985; Watanabe et al 1985; Laccheri, 1987; Moldowan, 1987; Stefan and Luc, 1997; Kempa, 2004; Hernandez, 2005; Olt, 2007; Beutler, 1984; Bernt and Gutman, 1974; Majki and Berkec, 1980).

Many difficulties and disadvantages are accompanied these methods. Some of them, especially the non-enzymatic methods, are complex and time consuming. They require previous separation process (distillation, pervarporation), expensive instrumentation and trained operators. Such disadvantages can be overcome by the use of enzymatic methods. In such enzymatic methods, most enzyme-catalyzed reactions can be followed by simple, widely available spectroscopic or electrochemical methods (Azevedo et al 2005).

Optical methods require an apparatus, such as a spectrophotometer. Moreover, such methods cannot be applied to turbid samples, such as blood or food samples. Furthermore, for carrying out the enzymatic reaction, a troublesome procedure involving dissolution of various reagents and distribution of the resulting solutions into reaction vessels in amounts specified beforehand is required, and the reagent solutions, such as prepared $\mathrm{NAD}^{+}$solution have poor storage stability. For these and other reasons, those methods are not suitable for general use. In order to overcome 
these difficulties, the combined use of an enzymatic method and an electrochemical method for determining alcohols have been desired (Watanabe et al 1985).The optical density in such assay must be read at $340 \mathrm{~nm}$, precluding the use of widely available and relatively inexpensive photoelectric colorimeters that do not allow precise determination in the UV range (Rodionov et al 2002). Additionally, in order to increase accuracy, there is a need to dilute the samples, due to the limitation of Lambert-Ber-Law's linearity.

Other spectroscopic methods (colorimetric, chemiluminescent and fluorescent methods) can be used to detect the production of $\mathrm{H}_{2} \mathrm{O}_{2}$ during the oxidation of ethanol. Most spectrometric methods are based on a bienzymatic system, comprising AOX and a peroxidase enzyme. The need for fast, cheap, sensitive and continuous analyzing methods with a high sample throughput led to application of immobilized enzyme reactors into flow system based analysis (Rodionov et al 2002).

Use of enzyme electrode or biosensor to detect changes in either oxygen concentration or $\mathrm{H}_{2} \mathrm{O}_{2}$ concentration in reactions, catalyzed by immobilized alcohol oxidase, suffers from some difficulties. Measurements based on oxygen have practical inconveniences and limitations. The response is low, and the dependency on oxygen can reduce the accuracy and reproducibility of the device. Moreover, because of a high background signal, the minimum detectable concentration is not very low. The detection of $\mathrm{H}_{2} \mathrm{O}_{2}$ is the most commonly used alternative to overcome these drawbacks. These techniques, however, usually suffer from low sensitivity (Rodionov et al 2002; Majki and Berkec, 1980).It has been reported that when ethanol was oxidized just in buffer by AOX, immobilized in $31 \mu$ l bioreactors, the conversion started to decrease after $3 \mathrm{~h}$ of continuous operation and after $4 \mathrm{~h}$ more than $80 \%$ of the initial conversion were lost. Also one of the main factors that affect the performance of a biosensor is the enzyme immobilization procedure itself (Azevedo et al 2005).

There seems to be no fully satisfactory method for wide range ethanol concentrations quantification available yet. The above mentioned methods are not only limited for a certain range of ethanol concentration, but also they have difficulties or problems as mentioned above. Furthermore, some of them are expensive.

Therefore, the aim of this study was to develop a simple enzymatic method for detection and quantification of a full range of ethanol concentrations without diluting of samples. During this method a reduction in the cost of the ethanol assay will be done by using a small quantity of one enzyme and very low $\mathrm{NAD}^{+}$concentration. The measurements will be achieved by using a simple device, a differential $\mathrm{pH}$ analyzer system CL10.

The basic principle of this method is to assay ethanol sample by measuring $\mathrm{pH}$ variation produced in the medium during the enzymatic oxidation of ethanol to acetaldehyde. This reaction is achieved in presence of alcohol dehydrogenase enzyme. The following reaction represents reaction mechanism:

$$
\mathrm{CH}_{3} \mathrm{CH}_{2} \mathrm{OH}+\mathrm{NAD}^{+} \leftrightarrow \mathrm{CH}_{3} \mathrm{CHO}+\mathrm{NADH}+\mathrm{H}^{+}
$$

\section{Experimental Procedure}

\subsection{Instruments}

\subsubsection{Differential pH analyzer system CL10 (Eurochem, Italy).}

This device mainly consists of one mixing chamber, five peristaltic pumps and two capillary glass electrodes of $\mathrm{pH}$ sensor. This apparatus is controlled by using the CL10 Manger program. Figure 1 shows the schematic diagram of this apparatus. Details on the principle of its work, measurement and control can be found in different publications (Luzzana et al 1983; Rovida et al 1984; Luzzana et al 2001).

\subsubsection{Spectrophotometer}

In order observe the enzymatic reaction of ethanol oxidation to acetaldehyde; spectrophotometer type (Specord 205 from Analytic Jena AG, Germany) was used. A rise in absorbance, which is stoichiometric with amount of formed $\mathrm{NADH}$, can be measured within spectrophotometer.

\subsubsection{Curtipot program}

A program was designed in order to execute $\mathrm{pH}$ and acid-base titration curves: Analysis and Simulation (Gutz, 2008).

\subsection{Materials}

$\beta$-nicotinamide-adeninedinucleotide (NAD+), Alcohol dehydrogenase enzyme ADH (EC 1.1.1.1), NADH were purchased from Sigma-Aldrich Company. High purity grade ethanol $(99.985 \%)$ was used in preparing standard ethanol samples. These samples of different concentrations $(0.00001714-17.14 \mathrm{M})$ were obtained by blending ethanol with bidest water of 0.005 microsiemens $(\mu \mathrm{S})$. Buffer solution with $\mathrm{pH}$ of 9.1 at $25^{\circ} \mathrm{C}$ was composed from $0.02 \mathrm{M}$ of glycine and $0.02 \mathrm{M}$ of sodium pyrophosphate. Solution of alcohol dehydrogenase enzyme with a final 
activity of (563.75 units $/ \mathrm{ml})$ was prepared by dissolving enzyme in a mixture of $25 \%$ of glycerol $/$ water. Magic N50 solution was prepared by blending $50 \mu 1$ of $50 \mathrm{mM} \mathrm{NAD}^{+}$with $100 \mathrm{ml}$ of the used buffer and $850 \mathrm{ml}$ of pure water. This $\mathrm{NAD}^{+}$solution was called by authors Magic N50 solution because the effective of its low concentration in analyzing full ranges of ethanol concentrations. KIT assay (K-ETOH, Megazyme International Ireland Ltd, 2006) was used in order to make economic comparison.

\subsection{Procedure}

The differential $\mathrm{pH}$ device was set to a temperature of $30^{\circ} \mathrm{C}$, a waiting time of 4 seconds and maximum reaction time (cycle time) of 300 seconds. First runs were done with buffer only as system check-up. For ethanol quantification, $50 \mu \mathrm{l}$ of sample were well mixed with $10 \mu \mathrm{l}$ of alcohol dehydrogenase enzyme to get $60 \mu 1$ of enzyme-ethanol complex in glass tube. $250 \mu \mathrm{l}$ of Magic N50 solution was injected into the mixing chamber which contained $1090 \mu \mathrm{l}$ of buffer. After 40 seconds the measurement cycle was started and about $315 \mu \mathrm{l}$ of this solution were then automatically distributed into electrodes 1 and 2. $50 \mu 1$ of enzyme-ethanol complex solution were added to $775 \mu \mathrm{l}$ of remaining solution in mixing chamber. The difference in $\mathrm{pH}$ of electrode 1 and electrode 2 was observed. The $\mathrm{pH}$ deviation is a result of ethanol conversion to acetaldehyde.

By the same procedure, differences in $\mathrm{pH}$ were measured for buffer solution devoid of sample and for buffer with only $250 \mu 1$ of Magic N50. These measurements were done in order to see the substances effect on system measurement.

Additionally, the reaction was observed by measuring the absorption of solution caused by the consumption of $\mathrm{NAD}^{+}$, or the formation of NADH during the conversion of ethanol to acetaldehyde within spectrophotometer at $340 \mathrm{~nm}$ of ultraviolet light.

\section{Results and discussion}

The differential $\mathrm{pH}$ analyzer system CL 10 was achieved detection of differences in $\mathrm{pH}$ between solutions. Thus, this device was used to measure change in $\mathrm{pH}$, which is caused by enzymatic alcohol dehydrogenize reaction, for samples containing $0-99,985 \%$ of alcohol.

After construction of delta $\mathrm{pH}$ value of buffer, the obtained delta $\mathrm{pH}$ values were in range from $-0.891 \mathrm{mpH}$ to $-33.269 \mathrm{mpH}$ for a full ethanol concentrations range of $0.00001714 \mathrm{M}-17.14 \mathrm{M}$ respectively. These obtained delta $\mathrm{pH}$ values are sufficient to be used in quantifying any ethanol concentration in sample. The required time to reach constant delta $\mathrm{pH}$ value, end point, is inversely proportional to the ethanol concentration and it is not exceed 100 seconds. These results can be shown in figure 2 .

The results indicated a nonlinear relationship between the alcohol concentration and the obtained change in $\mathrm{pH}$ as shown in figure 3 . The non linearity was because of change in ethanol concentration which caused a change in the enzymatic reaction order from first to zero order. As approved, the order of reaction will be changed from first order reaction for low substrate concentration to zero order for high substrate concentration (Dunn et al 2003; Murry, 2003; Lee 2001). Such nonlinear plot can not be used as a calibration curve for ethanol determination.

Since ethanol concentration is stoichiometric to librated $\mathrm{H}^{+}$according to equation1 and $\mathrm{pH}$ of solution is a logarithmic function of $\left[\mathrm{H}^{+}\right]$, a calibration curve was done by plotting the logarithmic value of ethanol concentrations against change in $\mathrm{pH}$ as shown in figure 4. This figure shows a linear relationship which can be used in quantification of ethanol concentration. Figure 4 consist of two parts a and $b$. Part a can be used for obtained change in $\mathrm{pH}$ up to $-2.7 \mathrm{mpH}$ while part $\mathrm{b}$ can be used for obtained change in $\mathrm{pH}$ starting from -3 up to $-33 \mathrm{mpH}$ as shown in figures (4.a \& 4.b). The correlation coefficient of the linear regression of calibration curve, $R$, was 0.988 which means that the difference between predicted values and observed values of ethanol concentration is too low. This suggestive of a good model fit. In addition to that Chi square test was applied in order to evaluate the calibration curve precision. Degree of freedom, n-1, for seven standard samples of ethanol is 6 . Therefore, for 6 degree of freedom and 0.05 probability, Chi critical table value is 12.592 (Snedecor and Corchran, 1989). The Chi square value was calculated 0.002 as shown in table 1. Since Chi square value is less than Chi critical table value, null hypothesis is accepted. That means there is no significant difference between the expected and observed values. In order to estimate the precision and the accuracy of the measurements, statistical evaluation for the results was made. In table 2, maximum standard deviation and maximum coefficient of variation for three replicates of measurements were 0.7 and $5.8 \%$ respectively. This low coefficient of variation range demonstrates that the measurements had little dispersion from the mean value which makes the results more precise and confidential.

To value the results, the oxidation reaction of ethanol to acetaldehyde was observed by measuring the change in absorption within spectrophotometer at $340 \mathrm{~nm}$. The change in absorption of solution was caused by the formation of NADH from $\mathrm{NAD}^{+}$during the conversion of ethanol to acetaldehyde. The absorption values can be shown in 
figures 5 and 6 . The results showed that the time required reaching end point of the reactions for standard ethanol samples was not exceeding 100 seconds. These results are satisfied the results obtained by measuring change in $\mathrm{pH}$ within differential $\mathrm{pH}$ analyzer system.

Curtipot program was used to estimate the capacity of the buffer and to measure the equivalent end point of traditional titration curve. The result indicated that the buffer of $0.02 \mathrm{M}$ of glycine and $0.02 \mathrm{M}$ of pyrophosphate will have one equivalent point, although it contained polyprotic acids, when it was titrated with $0.1 \mathrm{M}$ of $\mathrm{NaOH}$. This means it actually behaves like monoprotic acid and it is stable for the measurements as shown in figure 7 .

In order to see the stability of differential $\mathrm{pH}$ analyzer system CL10, the following two experiments have been done in absent of ethanol oxidation reaction. The changes in $\mathrm{pH}$ were measured for systems consist of either buffer only or by adding $250 \mu \mathrm{l}$ of Magic N50 solution to the buffer. The results indicated that glycine-pyrophosphate buffer was suitable to be used for this system as there was no noise in measurement. Also there was no noticeable influence of the Magic N50 solution on the measurement. The ability of these preparations to influence the measurement can be seen in figure 8 .

Additional experiments had been done for samples of ethanol concentrations from 0.1714 to $17.14 \mathrm{M}$. In these experiments Magic N50 solution was prepared from NAD ${ }^{+}$solution of $100 \mathrm{mM}$. The obtained delta $\mathrm{pH}$ values were increased by a factor of 1.6 in comparison with those using $50 \mathrm{mM}$ of $\mathrm{NAD}^{+}$as shown in figure 9 . The general behavior was still nonlinear. This indicates that there is no reason to increase the amount of $\mathrm{NAD}^{+}$for this ethanol essay as that will lead to increase the essay costs and will be on expensive of time too. The set up of differential $\mathrm{pH}$ analyzer device CL10 has a limit of 300 seconds of maximum reaction time. However, Magic N50 solution of $100 \mathrm{mM} \mathrm{NAD}^{+}$or more could be used if somebody wants a wide range of delta $\mathrm{pH}$ for his own standard calibration curve.

\section{Economic aspect}

In order to evaluate the economic aspect of this new method, a comparison with KIT method (K-ETOH) of Megazyme International Ireland Ltd was done. The results of this economic study (calculation is not showed) indicated that assaying 373 samples by using KIT method require using $1865 \mathrm{mg} \mathrm{NAD}{ }^{+}$, 5.6mg alcohol dehydrogenase (ADH) enzyme and $154.4 \mathrm{mg}$ aldehyde dehydrogenase (AL-DH) enzyme. However, applying the present method for assaying same number of samples utilizes $155 \mathrm{mg} \mathrm{NAD}{ }^{+}$and $4.7 \mathrm{mg}$ alcohol dehydrogenase enzyme. Aldehyde dehydrogenase enzyme was not used in the present method.

The above calculation demonstrates the following:

1. There is a factor of 12 in the number of samples that can be assayed for the same amount of $\mathrm{NAD}^{+}$, which means a noticeable cost reduction.

2. In addition to that, KIT assay uses two enzymes, alcohol dehydrogenase ADH and aldehyde dehydrogenase AL-DH, while we just have used one enzyme, alcohol dehydrogenase. It could be seen that the amount of alcohol dehydrogenase enzyme for our method is slightly less than of that used in KIT method.

Additional cost by applying Kit assay is to be considered due to the use of NADH. The use of KIT assay also needs an additional calibration curve of NADH absorbent because of the necessity of accurate quantification within spectrophotometer.

\section{Conclusions}

It is possible to detect full range of ethanol concentration with lowering the cost. The recent method is a development for enzymatic methods by reduction the number of required enzymes to one. Also there is no need to dilute samples during the analysis. This will decrease the errors which are happened by users often. Using logarithmic values of ethanol concentrations in making calibration curve bring new approach in concentration quantification by using change in $\mathrm{pH}$. This work offers the basis to start studies of full range concentrations quantification within differential $\mathrm{pH}$ measurement sensor device. Therefore, work in optimization is recommended.

\section{Acknowledgements}

This work was supported by Institute of Bioprocess Engineering at Erlangen University.

\section{References}

Azevedo, A. M., Miguel, F., Joaquin, M.S. \& Fonseca, L. P. (2005). Ethanol biosensors based on alcohol oxidase.

Biosensors and Bioelectronics, 21, 235-247.

Bauer, R. \& Magers, T. (1985). Enzymatic ethanol test. European patent 0164008, A2; B1. 
Bernt, E. \& Gutman, I. (1974). Determination with alcohol dehydrogenase and NAD. In: Methods in enzymatic Analysis. 3 rd edn, Edited by H. U. Bergmeyer, Academic press, New York: Vol. 3, pp. 1499-1502.

Beutler, H. (1984). In Methods of Enzymatic Analysis. 3rd edition, VCH, Weinheim-Deerfield Beach, FL-Basel,6, 598-606.

Dunn, L.J., Heinzle, E., Ingham, J. \& Prenosil, J.E. (2003). Biological reaction engineering. Second edition, Wiley-Vch, pp. 68-72.

Goodman, D. \& Jacksonville, F. (1975). Method for determining the ethanol content of alcoholic beverages. US patent 3896659.

Gutz, I. G. R. (2010). Curtipot program, Version 3.5.4, pH and Acid-Base titration curves: Analysis and Simulation [Online]. Available: http://www2.iq.usp.br/docente/gutz/Curtipot_html

Hernandez, F. (2005). Devices and methods for measuring ethanol content in blood. European patent 1873528 A1.

Kempa, E. (2004). Probe device for measuring ethanol concentrations in an aqueous solution. European patent 1439383 A.

K-ETOH, Ethanol assay procedure. (2006, 11/06). Megazyme International Ireland Ltd.

Laccheri, E. (1987). Reagent for the enzymatic determination of primary c1-c4 alcohols and related method. European patent 0240964 A1.

Lee, J. (2001). Biochemical engineering.๑ by James M.Lee,Department of chemical engineering, Washington State University, Pullman, WA 99164-2710, Chapter 2.pp. 19-69.

Luzzana, M., Agnellini D.\& Cremonesi, P. (2001). Enzymatic reaction for the determination of sugars in food samples using the differential pH technique. Journal of Analyst, 126, 2149-2152.

Luuzzana, M., Dossi, G., Mosca, A., Granelli, A., Berger, D., Rovida, M., Ripamonti, M., Musetti, A.\& Rossi-Bernardi, L. (1983). Measurement of glucose in plasma by a differential pH technique. Clinical Chemistry, 29, No.1, 80-85.

Majki, N. \& Berkec, I. (1980). Spectrophometric determination of ethanol by an enzymatic method with 2,2 -azino-di-(3-ethylbenz-thiazoline, 6-sulfonate). Anal.Chim.Acta., 115, 401-405.

Moldowan, M. J. (1987). Composition and method for ethanol determination. US patent 4642286.

Murray, R. (2003). Harpers illustrated biochemistry. 26 edition, McGraw-Hill Companies, Chapter 8, pp. 64-66.

Olt, R. (2007). Method and means for the enzymatic determination of ethanol. German patent, WO2007134683.

Rodionov, Yu.V., Keppen, O.I. \& Sukhacheva. (2002). A photometric assay for ethanol. Applied Biochemistry. \& Microbiology, 38, No.4, 395-396.

Rovida, E., Luzzana, M. \& Ripamonti, M. (1984). The determination of ethanol in whole blood by differential pH measurements, Scand.J.Clin.Lab.Invest, 44, 617-621.

Snedecor, G. \& Cochran, W. (1989). Statistical Methods, Eighth Edition, Iowa State University Press.

Stefan, S. \& Luc, T. (1997). Spectroscopic method. US patent 5679955.

Watanabe, M., Suzuki, T. \& Kageyama, M. (1985). Testing material for detecting alcohols. European patent 0154409 . 
Table 1. Statistical evaluation of the calibration curve: Chi square worksheet direction

\begin{tabular}{|c|c|c|c|c|}
\hline Ethanol sample (mM) & $\begin{array}{c}\text { Mean value } \\
\text { of obtained } \\
\text { change in } \\
\mathrm{pH}(\mathrm{mpH})\end{array}$ & $\begin{array}{c}\text { Observed } \\
\log [\text { ethanol] } \\
(\mathrm{O})\end{array}$ & $\begin{array}{c}\text { Expected } \\
\log [\text { ethanol] } \\
(\mathrm{E})\end{array}$ & $(\mathrm{O}-\mathrm{E})^{2} / \mathrm{E}$ \\
\hline 17147 & 33.269 & 4.234 & 4.226 & 0.008 \\
\hline 1714.7 & 24.519 & 3.234 & 3.289 & -0.055 \\
\hline 171.47 & 13.640 & 2.233 & 2.124 & 0.110 \\
\hline 17.147 & 5.876 & 1.233 & 1.292 & -0.059 \\
\hline 1.715 & 2.479 & 0.069 & 0.094 & -0.026 \\
\hline 0.172 & 1.623 & -0.931 & -0.983 & 0.052 \\
\hline 0.017 & 0.892 & -1.931 & -1.904 & -0.028 \\
\hline & & & & $\begin{array}{c}\sum(\mathrm{O}-\mathrm{E})^{2} / \mathrm{E}=0.002 \\
=\text { Chi square value }\end{array}$ \\
\hline
\end{tabular}

Mean values were multiplied by $(-1)$ as the measurements were in $(-\mathrm{mpH})$.

Table 2. Statistical evaluation of the measurements

\begin{tabular}{|c|c|c|c|c|c|c|c|}
\hline Ethanol sample $(\mathrm{mM})$ & 17147 & 1714.7 & 171.47 & 17.147 & 1.715 & 0.172 & 0.017 \\
\hline $\begin{array}{c}\text { Mean value of } \\
\text { obtained change in } \\
\mathrm{pH}(\mathrm{mpH})\end{array}$ & 33.269 & 24.519 & 13.64 & 5.876 & 2.479 & 1.623 & 0.892 \\
\hline Number of replicates & 3 & 3 & 3 & 3 & 3 & 3 & 3 \\
\hline Standard deviation & 0.377 & 0.116 & 0.703 & 0.247 & 0.098 & 0.079 & 0.052 \\
\hline $\begin{array}{c}\text { Coefficient of } \\
\text { variation \% }\end{array}$ & 1.1 & 0.05 & 5.2 & 4.2 & 3.9 & 4.9 & 5.8 \\
\hline
\end{tabular}

Mean values were multiplied by $(-1)$ as the measurements were in $(-\mathrm{mpH})$.

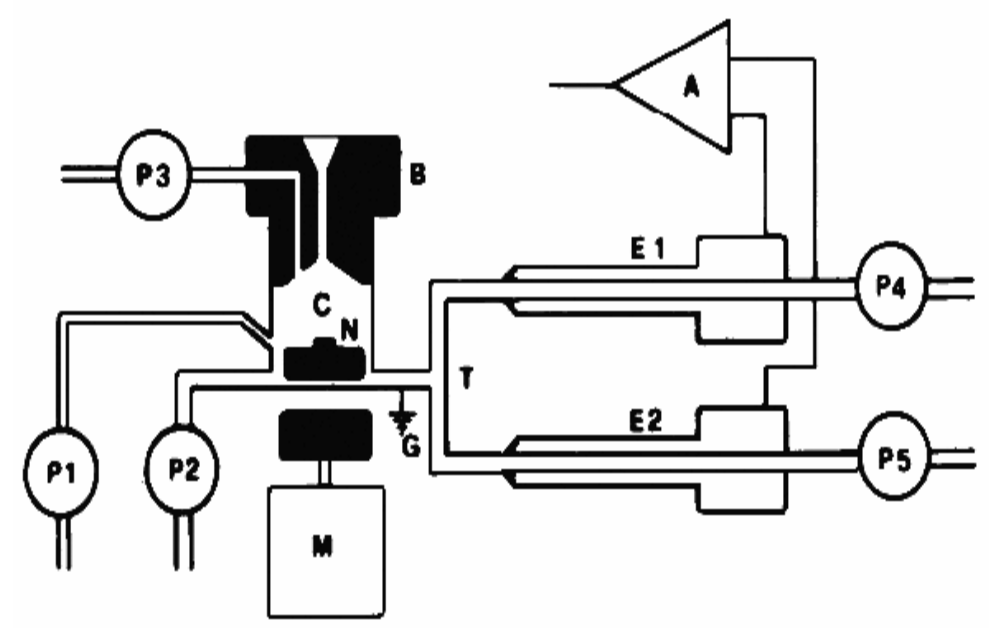

Figure 1. Schematic diagram of the differential $\mathrm{pH}$ analyzer system CL10.P1 to P5,peristaltic pumps; C, mixing chamber ; M, stirring motor ; N, magnetic stirrer ; E1 and E2, class capillary electrodes $\mathrm{pH}$ sensors ; A, differential amplifier (Luzzana et al 1983). 


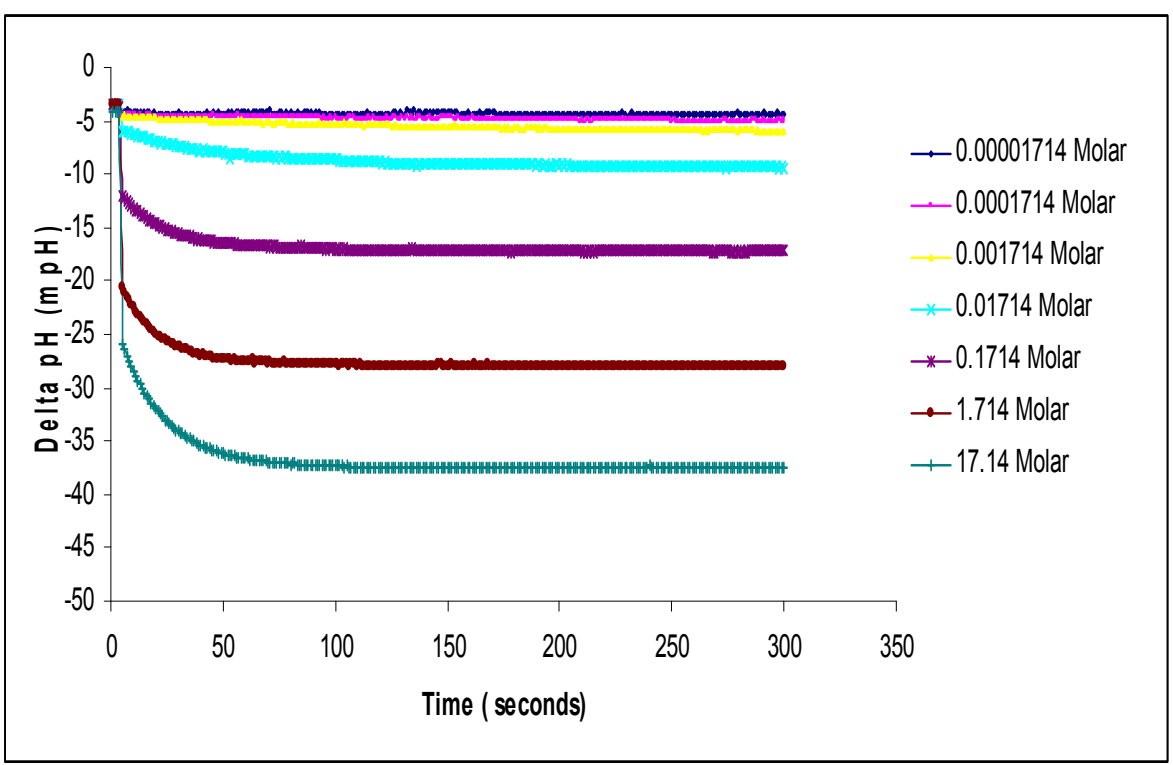

Figure 2. Delta $\mathrm{pH}(\mathrm{mpH})$ measured with time within differential $\mathrm{pH}$ analyzer system CL10 for different ethanol concentrations samples by using Magic N50 solution of 50mM NAD ${ }^{+}$. Each point is an average value of three measuring values

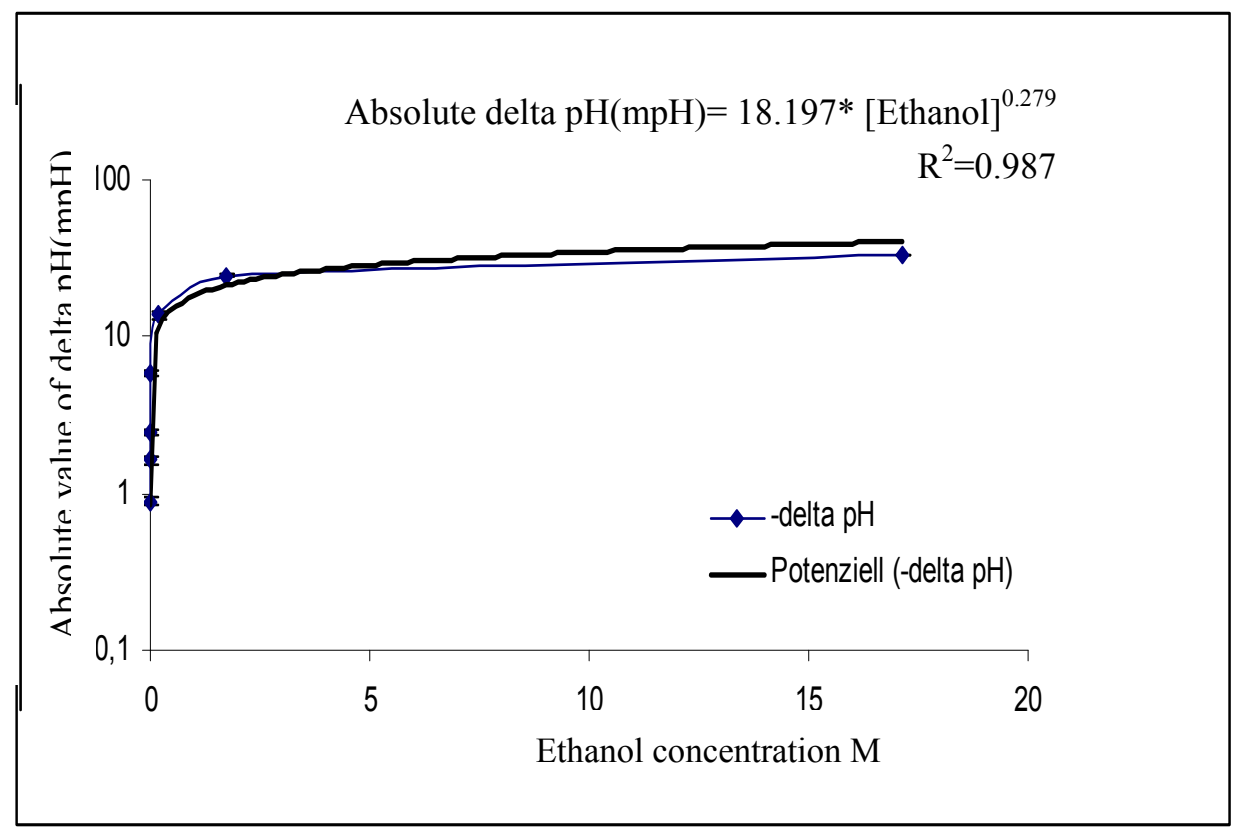

Figure 3. Delta $\mathrm{pH}(\mathrm{mpH})$ measured against different ethanol concentrations by Differential $\mathrm{pH}$ analyzer system CL10. Each point is an average value of three measuring values. The absolute values were obtained by multiplying the values of change in $\mathrm{pH}$ by $(-1)$ 


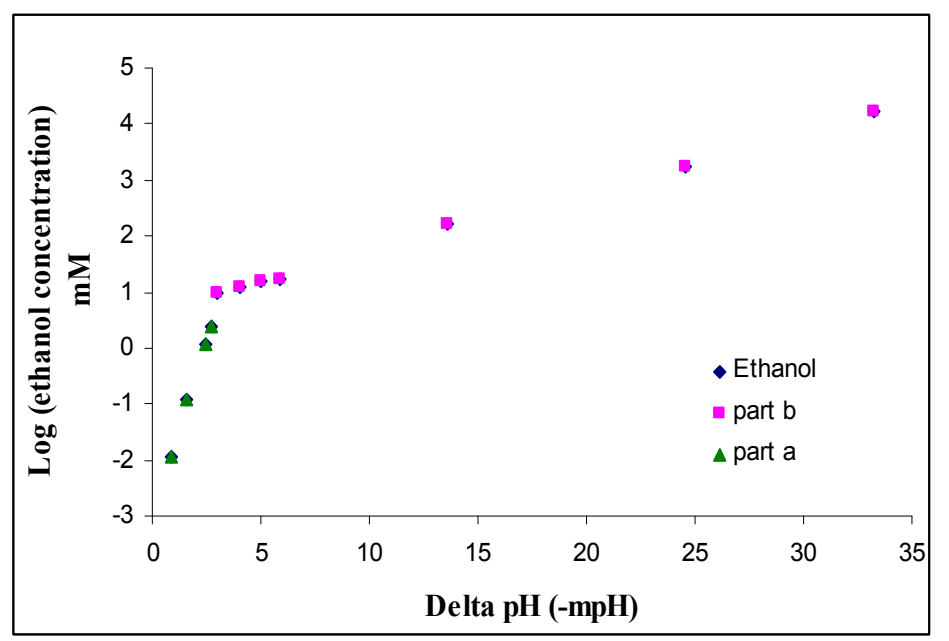

Figure 4. Calibration curves between logarithmic values of ethanol concentrations against change in $\mathrm{pH}$. Linear relationship was obtained. Change in $\mathrm{pH}$ is absolute value which was obtained by multiply the obtained change in $\mathrm{pH}$, delta $\mathrm{pH}$, by $(-1)$
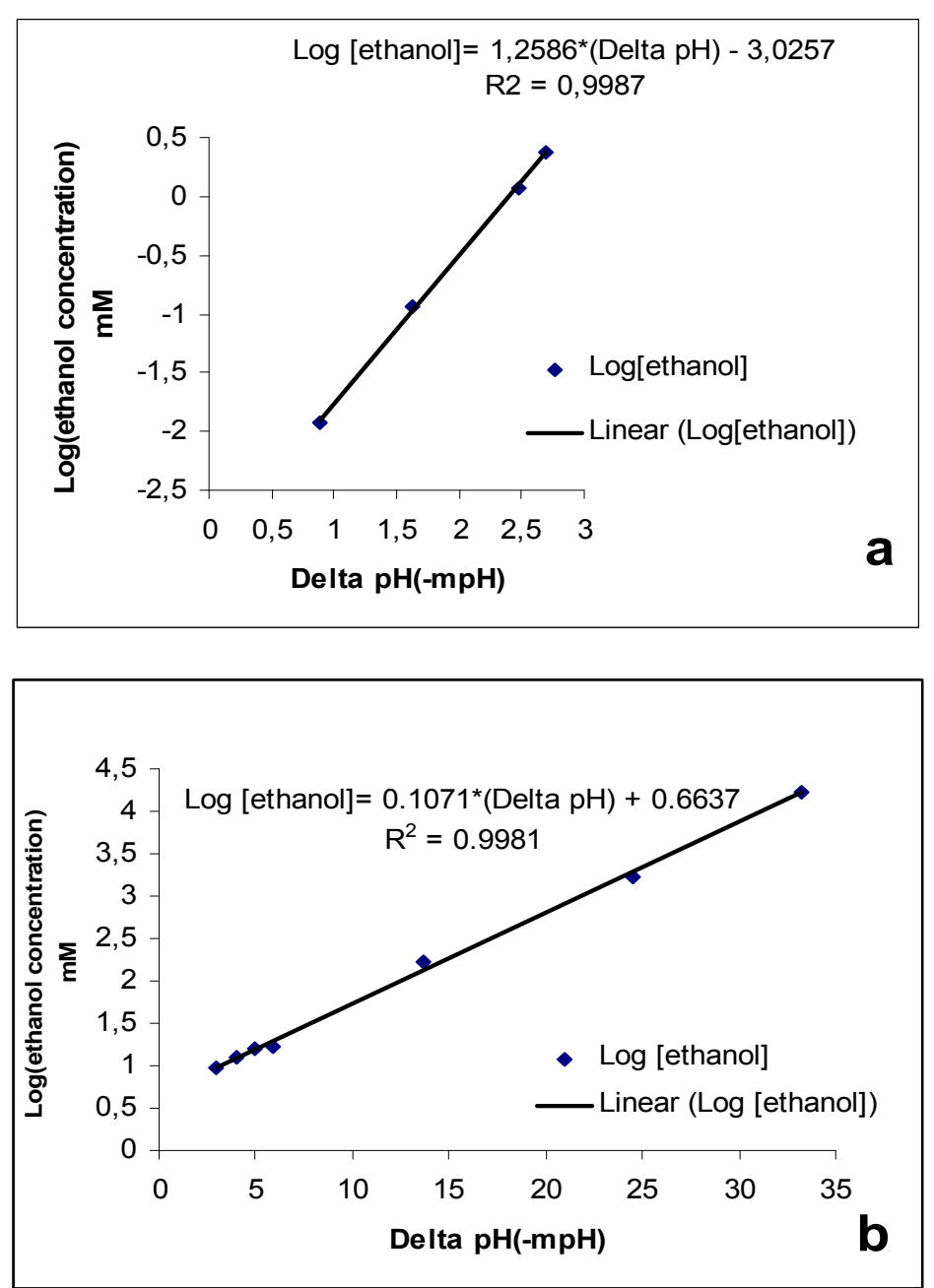

Figures (4.a and 4.b) Calibration curves between logarithmic values of ethanol concentrations against change in $\mathrm{pH}$. Change in $\mathrm{pH}$ is absolute value which was obtained by multiply the obtained change in $\mathrm{pH}$, delta $\mathrm{pH}, \mathrm{by}(-1)$.

(a) can be used for obtained change in $\mathrm{pH}$ up to $-2.7 \mathrm{mpH}$

(b) can be used for obtained change in $\mathrm{pH}$ starting from $-3 \mathrm{mpH}$. 


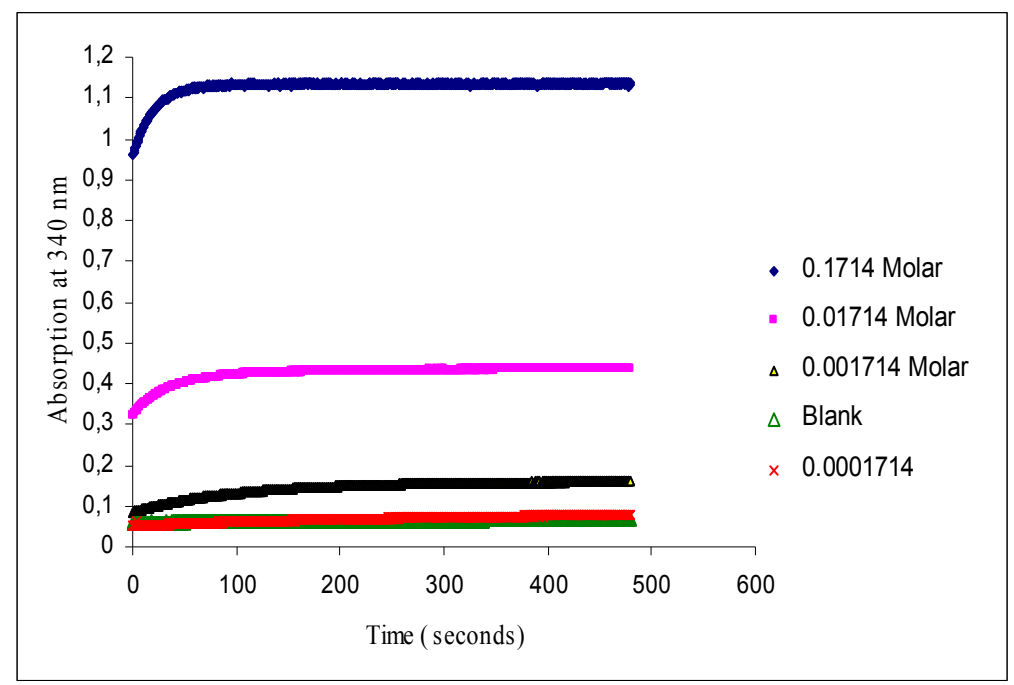

Figure 5. Absorption of formed NADH against time within spectrophotometer during Enzymatic Oxidation of different ethanol concentrations

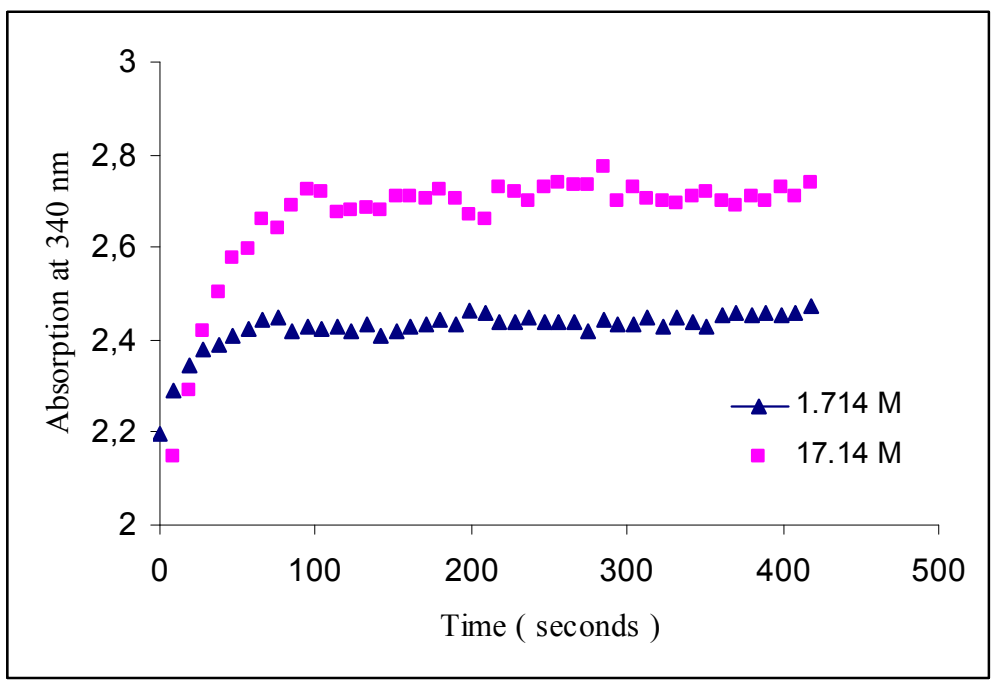

Figure 6. Absorption of formed NADH against time within spectrophotometer during Enzymatic Oxidation of different ethanol concentrations

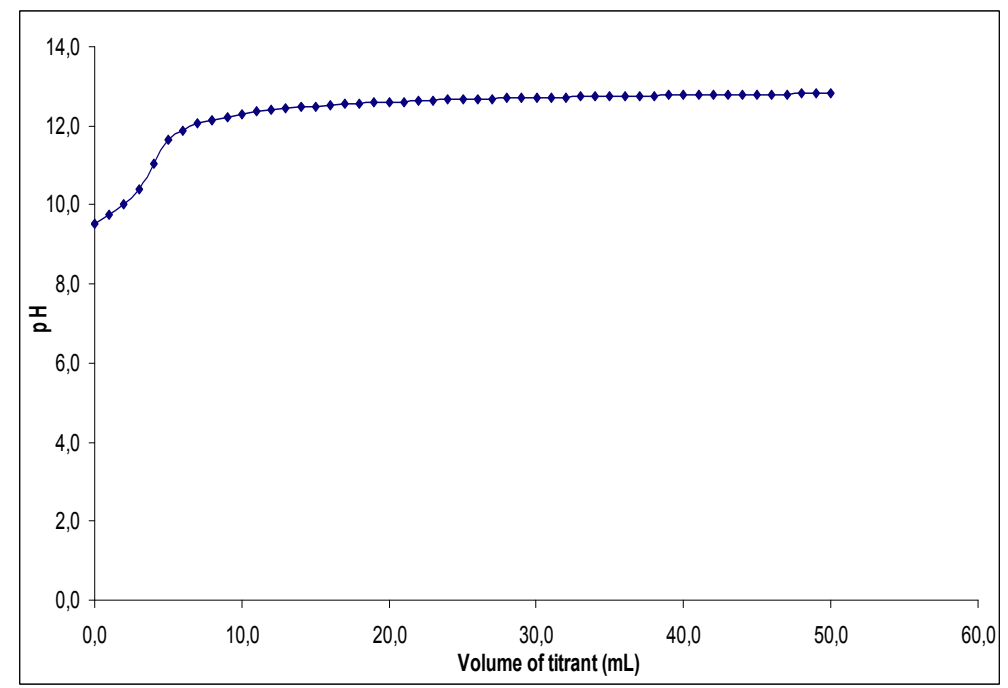

Figure 7. Titration of pyrophosphate-glycine buffer of $(20 \mathrm{~mL}, 0.02 \mathrm{~mol} / \mathrm{L})$ with $(0.1 \mathrm{~mol} / \mathrm{L} \mathrm{NaOH})$ 


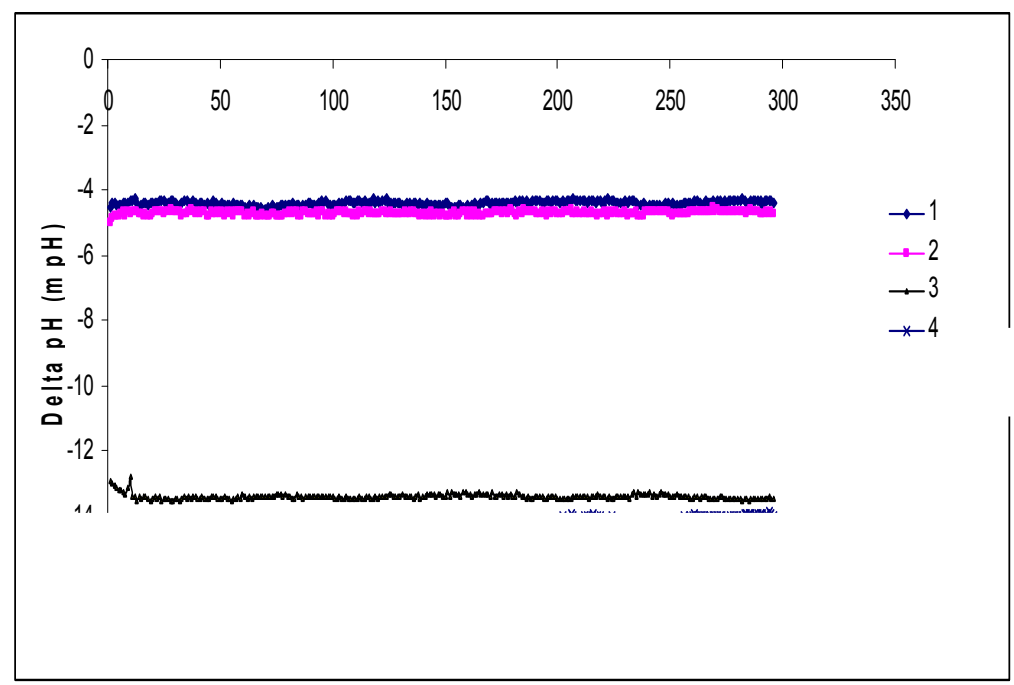

Figure 8. Observation of stability of differential $\mathrm{pH}$ analyzer system CL10.This measurements was devoid from ethanol oxidation reaction by using:

$$
\text { 1. only buffer }
$$

2. adding $250 \mu 1$ Magic N50 solution to the buffer

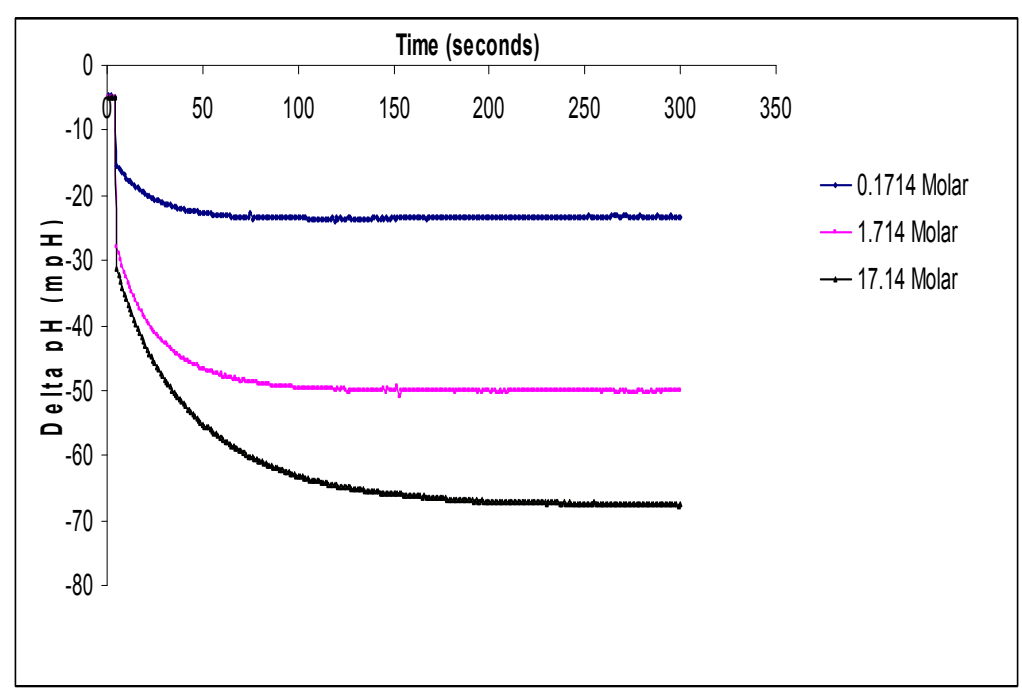

Figure 9. Delta $\mathrm{pH}(\mathrm{mpH})$ measured with time within differential $\mathrm{pH}$ analyzer system CL10 for three different ethanol concentrations samples by using Magic N50 solution of 100mM NAD+ 